\title{
The interaction of $\alpha$-synuclein and Tau: A molecular conspiracy in neurodegeneration?
}

\author{
Xu Yan, Riikka-Liisa Uronen, Henri J. Huttunen* \\ Neuroscience Center, Helsinki Institute of Life Science (HiLIFE), University of Helsinki, 00014 Helsinki, Finland
}

\section{A R T I C L E I N F O}

\section{Article history:}

Received 15 August 2017

Received in revised form 6 February 2018

Accepted 4 May 2018

Available online $\mathrm{xxx}$

\section{Keywords:}

Neurodegeneration

Network biology

Protein-protein interaction

Pathobiology

Interactome

\begin{abstract}
A B S T R A C T
$\alpha$-synuclein and Tau are proteins prone to pathological misfolding and aggregation that are normally found in the presynaptic and axonal compartments of neurons. Misfolding initiates a homooligomerization and aggregation cascade culminating in cerebral accumulation of aggregated $\alpha$-synuclein and Tau in insoluble protein inclusions in multiple neurodegenerative diseases. Traditionally, $\alpha-$ synuclein-containing Lewy bodies have been associated with Parkinson's disease and Tau-containing neurofibrillary tangles with Alzheimer's disease and various frontotemporal dementia syndromes. However, there is significant overlap and co-occurrence of $\alpha$-synuclein and Tau pathologies in a spectrum of neurodegenerative diseases. Importantly, $\alpha$-synuclein and Tau can interact in cells, and their pathological conformations are capable of templating further misfolding and aggregation of each other. They also share a number of protein interactors indicating that network perturbations may contribute to chronic proteotoxic stress and neuronal dysfunction in synucleinopathies and tauopathies, some of which share similarities in both neuropathological and clinical manifestations. In this review, we focus on the protein interactions of these two pathologically important proteins and consider a network biology perspective towards neurodegenerative diseases.
\end{abstract}

(c) 2018 Elsevier Ltd. All rights reserved.

\section{Contents}

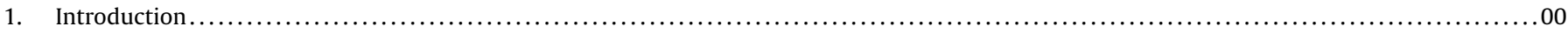

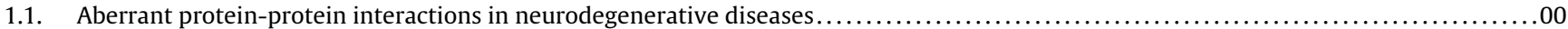

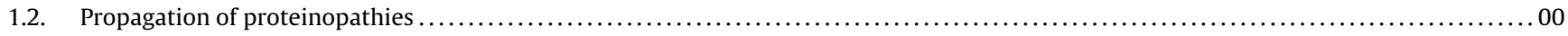

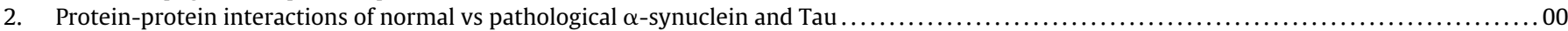

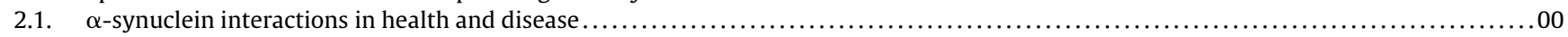

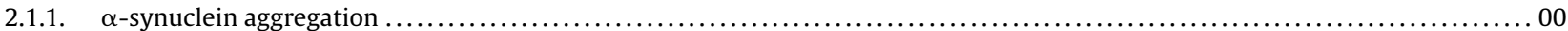

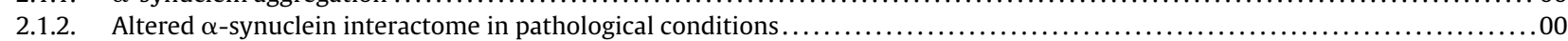

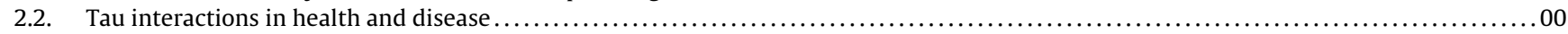

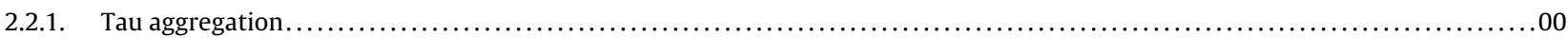

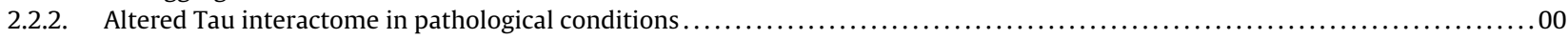

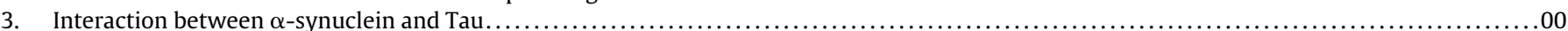

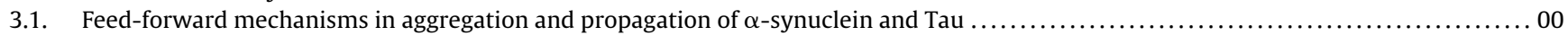

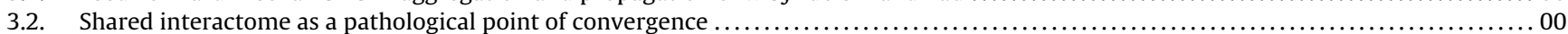

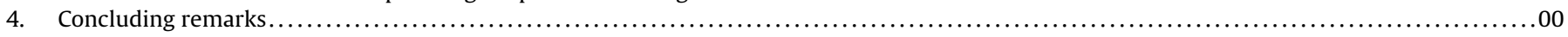

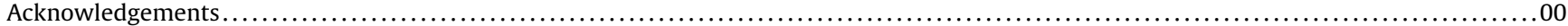

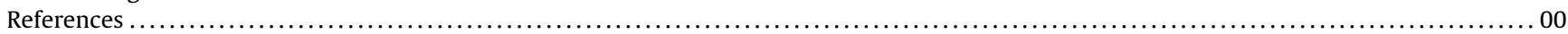

\footnotetext{
* Corresponding author.

E-mail address: henri.huttunen@helsinki.fi (H.J. Huttunen).
} 


\section{Introduction}

\subsection{Aberrant protein-protein interactions in neurodegenerative} diseases

Dynamic protein-protein interactions (PPIs) that constitute multi-protein complexes and networks are at the core of all cellular functions. Abnormalities in protein complexes and PPI networks are associated with various pathological disorders [1]. Misfolding and subsequent aggregation of normally soluble proteins into insoluble filamentous aggregates is a pathological hallmark shared by many neurodegenerative diseases [2]. Cerebral accumulation of aggregated forms of microtubule-associated protein Tau, in the form of neurofibrillary tangles (NFT), is a common feature of Alzheimer's disease (AD) and frontotemporal degeneration [3]. The accumulation of aggregated forms of $\alpha$-Synuclein (aSyn) in Lewy bodies (LB) is a hallmark of Parkinson's disease (PD) and dementia with Lewy bodies (DLB) [4].

Despite the fact that Tau and aSyn are distinct proteins and have been extensively studied in different pathological contexts, the mechanisms underlying their pathological aggregation and the consequences thereof appear to be converged and overlapping [5]. For example, both aSyn and Tau aggregation exhibit an inducible nucleation-elongation mechanism [2,6]. aSyn and Tau are cytosolic proteins predominantly expressed in neurons but are also commonly found in cerebrospinal fluid (CSF) of human patients, and the pathological forms of these proteins are transmissible between cells [7]. Tau and aSyn neuropathologies rarely exist in isolation and are often found to be accompanied with at least one other amyloidogenic protein such as $\beta$-amyloid (A $\beta$ ), TDP-43 and huntingtin. More than half of AD cases show LBs, and co-morbid AD pathologies, particularly NFTs, are commonly found in the brains of PD, DLB and PD with dementia (PDD) patients [5,8]. The associated aggregated proteins may have an impact on the clinical symptoms and disease progression, thus further affecting the neuropathological classification of the diseases. Tau is also a risk factor and mediator of parkinsonism, even in the absence of aSyn pathology [9]. Impor- tantly, aSyn and Tau can synergistically promote the aggregation and fibrillization of each other [10].

Pathologies associated with aSyn and Tau misfolding and aggregation may involve both gain-of-toxic-function features as well as loss-of-normal function features. Both proteins are normally predominantly localized in the axonal compartment of neurons where Tau functions as a microtubule-stabilizing protein and aSyn as a regulator of presynaptic vesicular trafficking $[11,12]$. Thus, lossof-function effects are most likely to primarily target axonal and presynaptic functions of neurons. Interestingly, several shared PPIs suggest that aSyn and Tau are involved in partially overlapping PPI networks. As the shared PPI networks are likely linked to cellular functions that are primarily affected when pathological aggregation of aSyn and Tau occurs, understanding the network biology connecting aSyn and Tau can provide new insight into disease mechanisms and therapeutic options. In this review, we will discuss the interactions between aSyn and Tau and provide an interactome perspective towards cellular dysfunction in tauopathies and synucleinopathies.

\subsection{Propagation of proteinopathies}

Both aSyn and Tau are natively unfolded proteins in monomeric form. Upon self-interaction or interaction with other proteins or membranes, both proteins are known to adopt more stable secondary and tertiary structures. Aggregation of aSyn and Tau occurs via misfolding, homo-oligomerization, and adoption of stable $\beta$-sheet structures $[13,14]$. Importantly, the pathological conformations of aSyn and Tau are capable of templating further misfolding and aggregation [15].

Pathological protein aggregation is a cascade of events, starting from a natively unfolded protein and culminating in the formation of insoluble protein aggregates and mature fibrils (Fig. 1). The pathological protein conformers can further transfer from one cell to another and seed aggregation of healthy proteins, thus transmitting the disease from one cell to another. Emerging evidence on the spread of various disease-associated proteins in a prion-

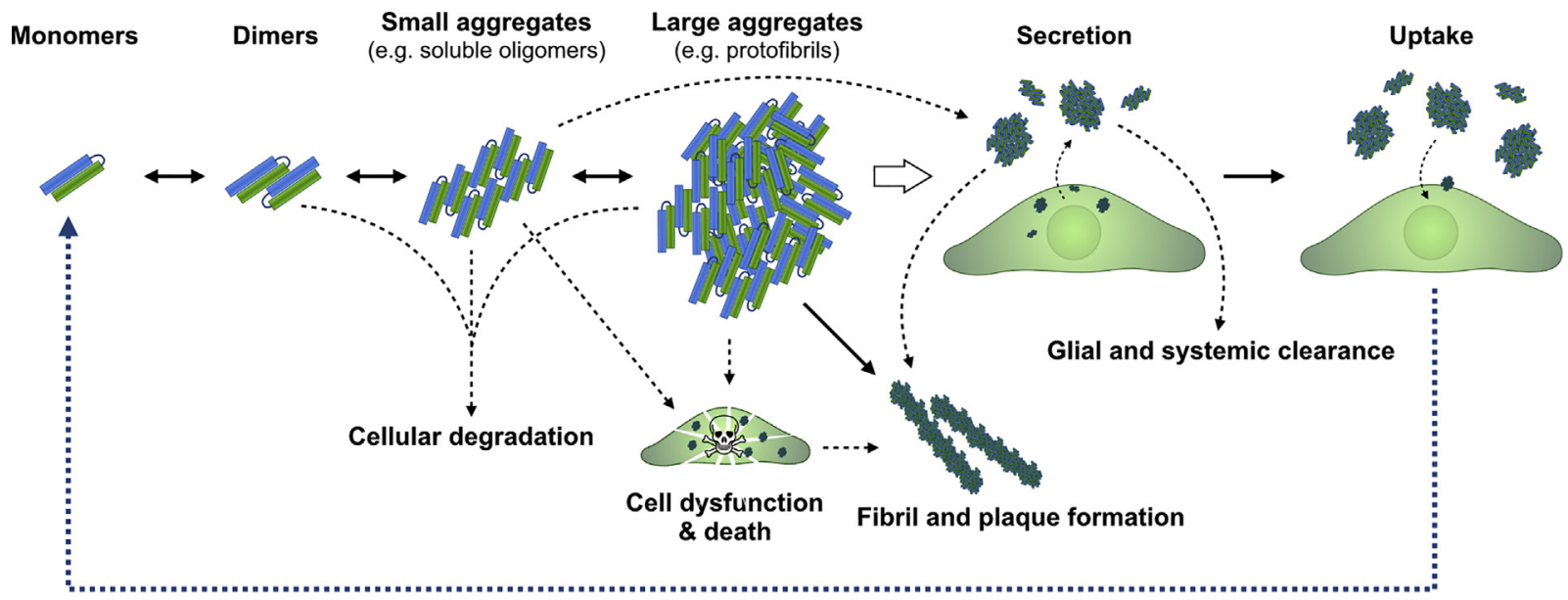

Templated seeding in newly affected cells (cell-to-cell transmission of proteinopathy)

\section{Loss of normal functions via lost interactions}

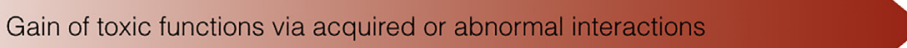

Fig. 1. Templated seeding of protein aggregation and cell-to-cell transmission of proteinopathies. 
likemanner in vitro and in vivo have implicated the existence of a common mechanism in the spread of pathology of neurodegenerative diseases [16]. The "prion-like propagation" paradigm holds that pathological conformers of amyloidogenic proteins, such as aSyn, Tau, A $\beta$, TDP-43, SOD1 and huntingtin, transmit between cells and spread pathology into distinct but connected brain regions with a mechanism similar to prion proteins. The exact mechanisms of cell-to-cell transfer and seeding of the disease-associated proteins remain poorly understood and generally involve four main stages: gain of seeding property, release from donor cells, uptake by recipient cells and templated misfolding of normal proteins in the recipient cells. Importantly, it should be considered that not only does the protein aggregation propagate from one cell to another but also the associated alterations in PPI networks of the affected proteins likely contribute to cellular dysfunction in the newly affected cells.

\section{Protein-protein interactions of normal vs pathological $\alpha$-synuclein and Tau}

\section{1. $\alpha$-synuclein interactions in health and disease}

\subsection{1. $\alpha$-synuclein aggregation}

aSyn is a 140 -amino acid protein encoded by the SCNA gene and forms the synuclein gene family together with the $\beta$ - and $\gamma$-synuclein. Aggregated aSyn is the major component of Lewy Bodies in various neurodegenerative diseases (synucleinopathies)[17]. There has been much controversy on the structure of normal aSyn protein and it seems that aSyn may context-dependently adopt secondary and quaternary structures [18]. Under normal circumstances, aSyn may exist in an equilibrium between unfolded monomers and folded multimers composed of 2-4 aSyn units [19]. Destabilization of the tetrameric forms of aSyn may serve as a mechanism for disease initiation by decreasing the solubility and increasing the toxicity of aSyn, as was shown for PD-causing aSyn mutations E46K and A53T [20]. Pathological forms of aSyn occur as ring- or pore-shaped oligomers, $\beta$-sheet intermediates and larger insoluble fibers and aggregates [2]. Oligomerization of misfolded aSyn results in aggregation that eventually leads to formation of inclusions, such as LBs (Fig. 1) [21]. aSyn seems to favour $\alpha$-helical structure upon binding to phospholipid membranes [22]. Lipid membrane serves as a 2D scaffold which modulates the local concentration and aggregation of aSyn [23].

Many factors contributing to aSyn aggregation are directly linked to aSyn structure. Some genetic mutations and posttranslational modifications, such as partial proteolytic cleavage, can alter aSyn structure to favour aggregation [2]. Other factors, such as phosphorylation, oxidative stress, fatty acids and distorted protein clearance mechanisms, can indirectly promote accumulation of aSyn aggregates. Proteins with chaperone activity towards aSyn, such as Hsp70 and several other heat-shock proteins, and some presynaptic proteins like Munc18-1 are important regulators of aSyn aggregation and toxicity [24,25]. In addition, there are other aSyn-interacting proteins with enzymatic activities, such as peptidyl prolyl isomerases FKBP12 and FKBP52 and prolyl oligopeptidase PREP, that interact with and promote oligomerization and aggregation of aSyn [26-28].

The non-amyloid component fragment (NAC) of aSyn composes the 35-amino acid (61-95) central hydrophobic region of the protein, which plays a major role in aSyn oligomerization and aggregation [29]. This hydrophobic motif may get exposed during misfolding and initiate aggregation. Mutation or deletion of this region significantly reduces aSyn filament assembly [30].

The mutations that are associated with familial forms of PD are mostly found at the N-terminal helix of aSyn. A30P, E46K, H50Q,
G51D and A53T mutations at the N-terminus have been associated with acceleration of aSyn fibrillization and increased aSyn toxicity [31]. These mutation-mediated effects were suggested to be a result of altered aSyn secondary structure (A30P, A53T), enhanced aSyn binding to phospholipids (E46K) and formation of aSyn fibrils that are more prone to activate proapoptotic pathways (G51D)[32-36].

C-terminal truncation of aSyn is a common post-translational modification, and the C-terminally truncated aSyn was found to be significantly enriched in Lewy bodies [37]. Tissue-specific expression of C-terminally truncated aSyn in nigral dopamine neurons was shown to markedly reduce dopamine levels in a transgenic mouse model, suggesting a failure to maintain aSyn-regulated dopamine homeostasis [38].

An early in vitro study demonstrated that the residues S87 and S129 of aSyn are constitutively phosphorylated [39]. However, it was later shown that aSyn phosphorylation is dynamic and that both phosphorylated forms of aSyn are significantly increased in Lewy bodies in both patient samples and animal models $[40,41]$. Phosphorylation of S87 was found to increase the conformational flexibility of aSyn, which leads to reduced binding affinity to lipid membranes and reduced potential to form fibrils [42]. In pathological conditions, aSyn forms phosphorylated at S129 are also often ubiquitinated. It appears that S129 phosphorylation plays a critical role in regulating cellular clearance of aSyn [43].

\subsubsection{Altered $\alpha$-synuclein interactome in pathological conditions}

In pathological conditions, the aSyn interactome can be altered resulting in both loss and gain of functions. As part of an effort to restore proteostasis, misfolded aSyn displays increased interactions towards a variety of chaperone proteins, with several examples from the Hsp90, Hsp70, Hsp60 and Hsp40 families (reviewed in [44]). Not surprisingly, increased levels or activity of chaperones has therapeutic effects in preclinical models of synucleinopathies [44].

At the presynapse, aSyn is normally associated with synaptic vesicles and interacts with SNARE proteins synaptobrevin-2 and VAMP2, promoting SNARE complex assembly. Via its role in presynaptic vesicle formation and fusion, aSyn regulates the release of neurotransmitters [12]. aSyn can also regulate dopamine (DA) transmission pathways via other mechanisms. aSyn interacts with and inhibits tyrosine hydroxylase $(\mathrm{TH})$, the rate-limiting enzyme in DA synthesis [45]. It may block TH phosphorylation directly via PPIs or activate protein phosphatase $2 \mathrm{~A}$ to dephosphorylate $\mathrm{TH}$ $[46,47]$. Synaptic deficits in aSyn overexpressing neurons and transgenic mice are thus likely related to altered synaptic functions of aSyn leading to a reduction in dopamine levels and catecholamine release as well as the presence of abnormal presynaptic vesicles $[45,48,49]$.

Disease-associated aSyn mutations and altered posttranslational modifications can alter aSyn PPIs. For example, the A53T mutation alters the secondary structure and conformational flexibility of the aSyn protein [50]. Consequently, aSyn A53T mutant protein shows enhanced interaction with neurofascin, an adhesion protein involved in maintenance of axonal integrity, and aSyn toxicity and the associated axonal degradation can be attenuated by neurofascin overexpression [51,52]. Some diseaseassociated aSyn mutations, including the E46K, A30P and G51D, alter the interactions of aSyn with lipids and membranes [53]. NMR data suggest that binding to the phospholipid membrane results in exposure of the hydrophobic areas of aSyn A30P and G51D mutants, which likely affects both protein aggregation mechanisms and PPIs of the mutant proteins [54]. Also, nuclear localization and histone interaction of aSyn was reported to associate with cellular dysfunction and toxicity, with A30P and A53T mutations exhibiting increased nuclear targeting [55]. 
Aberrant phosphorylation of aSyn impairs multiple important aspects of aSyn function and is associated with LB deposition of aSyn [41]. S129 phosphorylation is an important regulator of those interactions of aSyn that are involved in membrane interaction and vesicle trafficking [43]. In pathological conditions, aSyn hyperphosphorylated at S129 is extensively ubiquitinated, and S129 phosphorylation appears to play a critical role in mediating proteasomal degradation of aSyn [56]. In addition, phosphorylation at S129 and Y125 were shown to result in reduced interactions with proteins involved in mitochondrial electron transport chain complex while having increased interactions with proteins involved in cytoskeletal organization, vesicular trafficking and serine phosphorylation [57]. Interestingly, aSyn has been suggested to modulate apoptotic response to oxidative stress via its interactions with the mitochondria [58].

Homo-oligomerization is a process centrally involved in development of aSyn pathology. aSyn monomers and oligomers were shown to have different PPI profiles in synaptosomes [59]. Interestingly, majority of the synaptosomal aSyn-interacting proteins had a binding preference to aSyn oligomers. Many of these oligomerinteracting proteins are involved in cytoskeletal organization, such as actin, p25 $\alpha$, tubulin and mortalin, others are involved in calcium regulation, translation, vesicular trafficking, mitochondrial homeostasis and lysosomal degradation. Better understanding of which PPIs are specific for the pathologically misfolded aSyn oligomers in human brain should provide new insight into the PPI network perturbations occurring in synucleinopathies.

Changes in aSyn interacting proteins may also indirectly trigger aSyn misfolding and development of aSyn pathology. Mutations in GBA1, a gene that encodes glucocerebrosidase (GCase) enzyme with glucosylceramidase activity, lead to Gaucher disease, a lysosomal storage disorder [60]. It has been estimated that GBA1 mutations confer a 20 - to 30 -fold increased risk for PD, and that at least 5-10\% of PD patients carry a GBA1 mutation [61]. Under physiological conditions aSyn interacts with GCase selectively at the low $\mathrm{pH}$ of the lysosomal environment but the interaction is significantly reduced with the GCase N370S mutation [62]. The relationship between aSyn and GCase is complex as decreased GCase activity increases the levels and aggregation of aSyn but also aberrant aSyn species have been reported to downregulate GCase activity further contributing to disease progression [63,64].

Another interesting example of a disease-associated mutation in an aSyn-interacting protein is ATP13A2. Loss-of-function mutations in this endolysosomal transport ATPase result in an early-onset form of PD due to enhanced aSyn aggregation and increased exosomal secretion of aSyn that culminates in accelerated cell death and neurodegeneration $[65,66]$. Altogether, functional studies of GBA1 and ATP13A2 mutations suggest that impaired lysosomal function and altered aSyn PPIs in this compartment can lead to pathological accumulation of aSyn.

\subsection{Tau interactions in health and disease}

\subsubsection{Tau aggregation}

Tau has been long known for its physiological role in regulating microtubule assembly and stability [11]. It is a protein of 440 amino acids at full length and belongs to the microtubule-binding protein (MAP) family. Tau is encoded by the MAPT gene on chromosome 17q21 and has six splicing isoforms [67]. Isoforms that have four instead of three microtubule-binding domains (MBD) appear to be more prone to aggregation. Tau protein is structurally divided into acidic region, proline-rich region, microtubule-binding repeat region and C-terminal region [68]. The four regions constitute two functional domains: the $\mathrm{N}$-terminal projection domain ( $\mathrm{N}$-domain) and the microtubule-binding domain (R-domain).
Tau aggregation follows a similar pattern of nucleationelongation mechanism as aSyn. Several factors contributing to the aggregation process are shared between aSyn and Tau, such as structural characteristics favouring aggregation - mutations, truncations and post-translational modifications [6]. Also, several biomolecules, such as heparin and free fatty acids, are known to promote Tau aggregation [69,70].

It is widely recognized that hyperphosphorylation is a major contributor to Tau aggregation [6]. As the longest Tau isoform has $>80$ potential phosphorylation sites, the phosphorylation patterns of Tau are highly complex and remain incompletely understood. Under physiological conditions, Tau binds and stabilizes microtubules, and its phosphorylation homeostasis is maintained by transient interactions with kinases and phosphatases. However, abnormal phosphorylation of Tau occurs when the phosphorylation/dephosphorylation cycle is disturbed resulting in accumulation of hyperphosphorylated, non-microtubule-associated Tau in cells [6]. These forms of Tau can further oligomerize, eventually forming fibrils known as paired helical filaments (PHF), which are further organized to NFTs, the neuropathological hallmark of tauopathies [71]. However, it should be noted that reversible hyperphosphorylation of Tau without development of pathology has been observed in the brains of hibernating animals indicating that hyperphosphorylation alone may not be sufficient to trigger Tau aggregation [72].

While natively unfolded Tau monomers are structurally highly dynamic, Tau aggregates are generally packed into well-ordered $\beta$-sheet-like structures [73,74]. Two hexapeptides VQIINK and VQIVYK on second and third MBDs of Tau are essential for the formation of "zipper-like" interdigitated $\beta$-sheet structures, and thus play a key role in mediating Tau aggregation [75]. Certain FTDP-17 mutations, e.g. P301L, promote $\beta$-sheet formation and accelerate Tau aggregation [76,77].

Truncation is one of the post-translational modifications that are closely linked with the aggregation properties of tau. There are multiple potential protease cleavage sites on full-length tau. Truncations of Tau lead to various fragments containing the microtubule-binding region that are highly prone to aggregation [6]. Inoculation of mice with truncated forms of Tau induces aggregation of endogenous Tau and development of neurofibrillary pathology $[78,79]$.

\subsubsection{Altered Tau interactome in pathological conditions}

The N-terminal projection domain of Tau interacts with a variety of signalling proteins including Src-family kinases, phospholipase C- $\gamma$, Grb2 and Pin1 [80]. The microtubule-binding domain functions primarily through the four highly conserved MBDs that mediate the interaction of Tau with microtubules [73]. Tau physiologically interacts with several proteins abundant in the postsynaptic termini including Fyn kinase, PSD-95 and NMDA receptor, suggesting that Tau could be involved in synaptic plasticity. Silencing of Tau in mice impairs long-term potentiation further implicating Tau in NMDA receptor-dependent memory [81,82]. However, silencing Tau expression in neuronal culture does not trigger neurodegeneration or prevent axon growth most likely due to functional compensation by other MAPs [83]. Hence it has been suggested that neurodegeneration in tauopathies is more strongly correlated with the gain of toxic functions rather than loss of normal functions of Tau [6].

Altered Tau interactome is likely associated with gain of toxic functions in pathological conditions. For example, Tau in AD brain showed significantly increased interactions with ribosomal RNA-binding proteins compared to Tau from healthy brain [84]. Importantly, this was associated with impaired ribosomal function and reduced translation of PSD-95, a key synaptic protein. As protein synthesis is required for consolidation of long-term memory, 
this likely contributes to the impairment of cognitive functions in $\mathrm{AD}$ and other tauopathies.

As both physiological MT-regulating functions of Tau and its aggregation propensity are regulated by the phosphorylation status of Tau [85], altered interactions with kinases and phosphatases likely play an important role in development of Tau pathology. Akt1 was suggested to serve as a major regulator of Tau biology as it regulates several Tau kinases, such as GSK3 $\beta$ and PAR1/MARK2, and the protein quality control and degradation machinery through the Tau ubiquitin ligase CHIP [86]. As many of the serine/threonine residues phosphorylated in Tau are proline-directed, interaction with the prolyl cis/trans isomerase Pin1 is an important regulator of Tau dephosphorylation [87]. Notably, Pin1 expression is inversely correlated with neurofibrillary degeneration in AD brain and Pin 1 knockout mice show age-dependent neuropathy with hyperphosphorylated filaments of endogenous Tau [88].

Hyperphosphorylation promotes Tau interaction with c-Jun Nterminal kinase-interacting protein 1 (JIP1), a protein associated with kinesin motor protein complex, and impairs the function of kinesin complex while normal Tau does not [89]. This offers a potential mechanistic explanation for the frequently observed axonal transport impairment in $\mathrm{AD}$. Interestingly, in response to acute oxidative and heat stresses, dephosphorylated Tau accumulates in the nucleus where it binds and protects DNA from oxidative damage and possibly also enhances DNA repair [90]. Other Tau PPIs potentially altered in pathological conditions includes histone deacetylase 6 , a tubulin deacetylase involved in protein sorting and transport in the autophagy pathway $[91,92]$ and Otub1, a Tau deubiquitinating enzyme [93].

One potential driver of altered PPIs is abnormal subcellular localization of a protein. Hyperphosphorylation results in missorting of axonal Tau to the somatodendritic compartment where Tau interacts directly, in a phosphorylation-dependent manner, with the PSD-95-NMDA receptor complex [82]. Importantly, Taudependent dendritic sorting of Fyn promotes $A \beta$-induced, NMDA receptor-mediated excitotoxicity, which constitutes an important link between neuronal dysfunction and clinical symptoms of AD [94]. Fyn also hyperphosphorylates Tau in an A $\beta$-dependent manner [95]. Moreover, mislocalized Tau can recruit tyrosine ligase-like enzyme 6 (TTLL6) into dendrites which triggers Spastin to sever microtubules resulting in dendritic spine degeneration [96].

Several disease-associated mutations of Tau alter its interactome. FTDP-17 related mutations, such as P301L/S, G389R, R406W, G272V, K280 and V337M, not only strongly promote Tau-Fyn interaction but also drastically reduce Tau-PP2A interaction, resulting in hyperphosphorylation and aggregation of Tau [97]. Some FTDP-17 mutations, e.g. $\Delta \mathrm{K} 280$ and $\mathrm{P} 301 \mathrm{~L}$, also attenuate microtubulebinding of Tau, increase cytosolic Tau and thus indirectly promote aggregation [76]. While normal Tau interacts with several chaperones and proteasomal proteins [98,99], mutations such as P301L can disrupt these interactions, suggesting that some mutations may specifically impair mechanisms aiming to restore proteostasis in the presence of pathological Tau [100]. Moreover, as the C-terminus mediates the interactions of Tau with chaperones and proteasomal proteins, C-terminal truncations may promote accumulation of truncated forms of Tau by reducing interactions with the protein degradation machinery. Interestingly, Pin1 has opposite effects on wild-type Tau and the P301L mutant protein [101], highlighting the complexity of functional alterations of Tau interactome in various tauopathies. Under physiological conditions, Tau also interacts with membranes and this interaction can be affected by diseaseassociated mutations as is the case with the FTDP-17 mutation R406W, which disrupts the interaction between Tau and Annexin A2, a membrane cytoskeleton linker [102].

Secreted pathological Tau conformers internalized to healthy cells may cause cellular dysfunction via acquired abnormal PPIs.
We recently showed that internalized Tau oligomers display a significantly increased interaction with an RNA-binding, stressgranule protein TIA-1, which resulted in altered stress granule (SG) clearance dynamics and reduced cell viability [103]. SGs are cytoplasmic, non-membraneous RNA-containing foci that form transiently as a cellular response to various stresses. TIA- 1 is one of the self-aggregating RNA-binding proteins that regulate SG formation. Interaction with TIA-1 further promotes Tau misfolding and toxicity and abnormal SGs could serve as a platform for templated seeding of protein aggregation [104].

\section{Interaction between $\alpha$-synuclein and Tau}

\subsection{Feed-forward mechanisms in aggregation and propagation of $\alpha$-synuclein and Tau}

Pathological misfolding of a protein elicits stress on the proteostatic machinery of cells, which in chronic conditions can affect the folding of other aggregation-prone proteins eventually resulting in global dysregulation of protein homeostasis [105]. A recurrent theme of neurodegenerative diseases is the frequent co-occurrence of different disease protein aggregates in the same patient. For example, aSyn and Tau inclusions co-occur in multiple diseases including Lewy body variant of $\mathrm{AD}$, DLB and PD with dementia [5,106-108]. Phosphorylated forms of Tau are also found in Lewy bodies [109]. PD patients have increased risk of developing dementia, and NFTs are frequently observed at autopsy of late-stage PD patients while $>50 \%$ of $\mathrm{AD}$ patients have Lewy bodies at autopsy, suggesting remarkable cross-talk between synucleinopathies and tauopathies [8,110-114]. Moreover, mutations in the SNCA and MAPT genes, encoding the aSyn and Tau proteins, can both lead to disease phenotypes characterized by parkinsonism and dementia [32,115-118].

Despite the fact that aSyn and Tau are distinct proteins that primarily contribute to different disease-specific pathologies, multiple lines of evidence suggest that aSyn and Tau interact, modulate the aggregation of each other and co-exist in pathological inclusions in human brain [5]. aSyn directly interacts with Tau [119] and can induce all six isoforms of Tau to aggregate, while neither $\beta$-synuclein nor $A \beta$ peptide have this effect [10]. The A53 T mutation enhances aSyn-induced Tau fibrillization [120]. Conversely, the presence of pathological forms of Tau can accelerate aSyn fibrillization [10]. Tau overexpression alters aSyn aggregation pattern, reducing the number but increasing the size and toxicity of aSyn aggregates [121]. aSyn may indirectly modulate Tau aggregation by promoting Tau phosphorylation changes associated with negative regulation of microtubule stability [122]. aSyn also increases GSK3 $\beta$-mediated phosphorylation of Tau at AD-associated phosphoepitopes T181, S396 and S404 [123,124], and aSyn mutations A30P, A53T and E46K enhance the interaction with GSK3 $\beta$.

aSyn and Tau may influence cell-to-cell transmission of each other but the mechanisms remain poorly understood. Inoculation of pathological conformers of aSyn or Tau into healthy tissue has been shown to cross-seed aSyn or Tau aggregation in animal models (reviewed in [16]). Preformed aSyn fibrils promote intracellular aggregation of Tau in cells overexpressing both aSyn and Tau, and this effect was enhanced by P301L Tau mutation [125]. Interestingly, certain chaperone complexes may specifically regulate extracellular release of both aSyn and Tau, as was recently shown for Hsc70/DnaJC5 [126].

In PD, LBs are predominantly found in midbrain structures such as the substantia nigra and are morphologically different from those found in the cortical regions [127]. On the other hand, NFTs are more frequently detected in limbic and neocortical areas than in the midbrain [128]. Interestingly, distinct strains of aggregated 


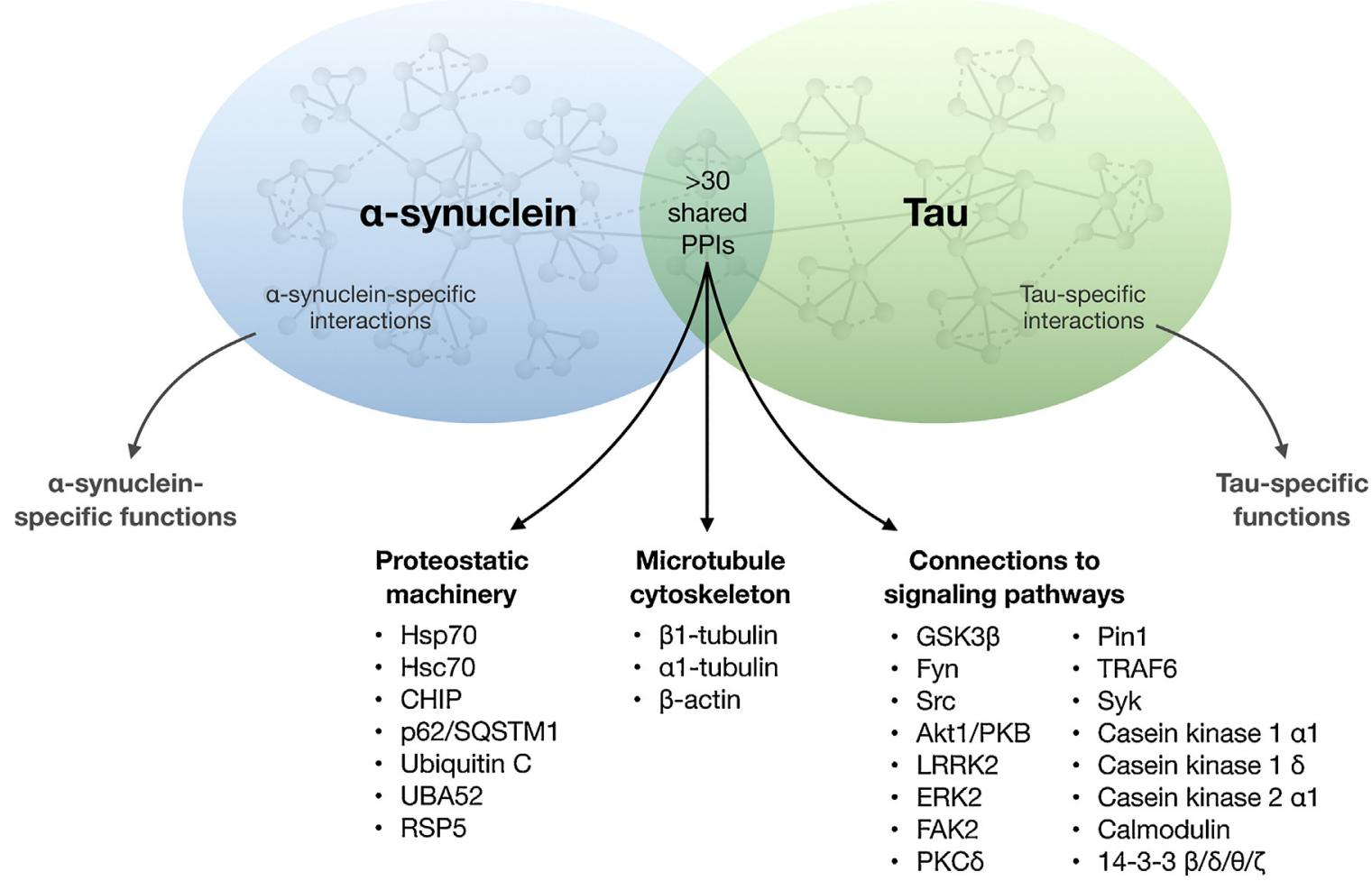

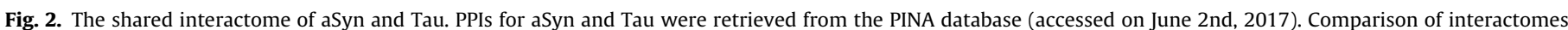
using the Cytoscape plugin PINA4MS identified 33 shared PPIs (approximately 7\% of all retrieved PPIs).

aSyn were found to differentially induce Tau hyperphosphorylation and aggregation $[125,129]$. As there are conformational variations in pathological aSyn species between regions in the human brain, the differential cross-seeding capacity of aSyn strains could explain the observed region-specific distribution of co-occurring LBs and NFTs [127]. Importantly, more direct in vivo evidence of crossseeding of pathologies involving aSyn and Tau, as well as other similar pathologically misfolded proteins, is needed.

\subsection{Shared interactome as a pathological point of convergence}

The diversity of clinical manifestations of a disease can be related to the connectivity patterns of the associated protein interaction network. In general, there is a strong correlation between symptom similarity and shared PPIs between diseases [130]. Neurodegenerative diseases are well known to display significant overlap of symptoms and neuropathological characteristics. For example, while many tauopathies are associated with progressive cognitive impairment, tauopathies with parkinsonism represent a spectrum of disease entities with predominant tau pathology but prominent parkinsonian symptoms [2].

Apart from the gain-of-function relationship that feeds forward the aggregation of each other, aSyn and Tau may also overlap in their loss-of-function effects. Aside of the numerous specific PPIs, aSyn and Tau share a number of interacting proteins (Fig. 2). These shared PPIs fall roughly in three functional categories: microtubule cytoskeleton, proteostatic machinery and protein phosphorylation/signal transduction. As protein interaction subnetworks tend to connect proteins in functional modules and pathways, it is plausible that a molecular defect in a shared network, such as extensive aggregation of one protein, either aSyn or Tau, could trigger loss-offunction effects on the other or on the cellular functions that both proteins are associated with, by spreading along the edges of the network.
Not surprisingly, aSyn and Tau share many interactions with proteins of the proteostatic machinery, including chaperones and components of the UPS and ALS systems (Fig. 2). Ubiquitinated forms of aSyn and Tau, together with UPS components, are found in LBs and NFTs [131,132]. Moreover, UPS and ALS impairments are frequently observed in synucleinopathies and tauopathies $[133,134]$. In general, overloading the cellular waste management systems by one aggregating protein species can lead to accumulation of other aggregation-prone proteins. As aSyn and Tau share multiple chaperones, accumulation of aggregated aSyn may promote Tau misfolding through chaperone competition, and vice versa.

Both aSyn and Tau are expressed in neurons where they localize predominantly to the axonal/presynaptic compartment. As neurons are highly polarized cells, the structure and functionality of cytoskeleton is critical for their viability. Both Tau and aSyn interact with tubulins. While Tau serves as a microtubule stabilizer, aSyn was reported to enhance tubulin polymerization [135-137]. Altered microtubule assembly and stability is thus a possible common loss-of-function target in pathologies involving aSyn and Tau misfolding. In pathological conditions, aSyn and Tau have been reported to mislocalize to the somatodendritic compartment, which may result in changes in their respective interactomes contributing to cellular dysfunction $[94,138,139]$.

One important cellular compartment for both gain- and lossof-function effects are the membranes. Membrane turnover has a particularly important role at the presynapse and is thus tightly regulated. Membranes with altered function have been observed in AD and PD [140-142]. Lipids are also found to colocalize with aSyn and Tau in LBs and NFTs [143,144], and lipid binding modulates aggregation properties of aSyn and Tau [145-148]. Upon binding to cell membranes, annular protofibrils of aSyn adopt an octameric structure similar to bacterial pore-forming toxins, resulting in increased permeability of membranes and influx of calcium [149-151]. Similarly, disruption of membrane integrity may partially explain the 
toxicity of Tau oligomers [152]. Thus, the normal function of the presynapse may be compromised by misfolded and aggregated forms of aSyn and Tau. It is currently not known if membraneembedded annular oligomers of aSyn and Tau can exist in the form hetero-oligomers or if they interact with other membrane proteins.

Many of the kinases that interact with both aSyn and Tau are either membrane-anchored or operate at the membranecytoskeleton interface. 14-3-3 proteins are small ubiquitous adaptor proteins that serve as regulators in diverse cellular processes, often in phosphorylation-dependent manner and in close association with membranes. Several members of the 14-3-3 adaptor protein family bind to both aSyn and Tau, and modulate their PPIs, phosphorylation and clearance mechanisms [153,154]. Interestingly, 14-3-3 proteins and aSyn share both physical and functional homology [155].

Certain disease-associated proteins interact with both aSyn and Tau. One interesting example is LRRK2, a kinase genetically associated with PD that phosphorylates both aSyn and Tau [156,157]. LRRK2 specifically binds to and phosphorylates tubulin-associated Tau at Thr181, promoting its dissociation from microtubules [158]. In addition, LRRK2 can indirectly promote Tau phosphorylation at Ser396 via its interaction with GSK3 $\beta$ [159]. In a similar manner, aSyn can also form a heterotrimeric complex with GSK3 $\beta$ and Tau and promote GSK3 $\beta$ 's kinase activity towards Tau [160]. LRRK2 G2019S, a common PD-associated missense mutation, promotes phosphorylation of both aSyn [157] and Tau [158], and is also associated with changes in Tau and aSyn expression in patient-derived stem cells [161]. Other mechanisms, such as impaired autophagy and axonal transport, may also affect aSyn and Tau and contribute to the overall pathogenic effects of LRRK2 [162].

In summary, the shared interactome of aSyn and Tau points to several cellular pathways known to be crucial for viability of neurons that may be affected by network perturbations initiated by pathological forms of aSyn and Tau. Nevertheless, it should be noted that both aSyn and Tau have functional homologues and thus functional compensation should be taken into account when discussing the loss-of-function effects. Although silencing Tau in neuronal culture does not trigger neurodegeneration or prevent axon growth [163], aged Tau knockout mice have dementia and parkinsonian phenotypes depending on the background strain [164]. While knockdown of aSyn results only in a modest changes presynaptic vesicles, possibly due to functional compensation by other synucleins $[165,166]$, triple knockout of all three synucleins triggers age-dependent neurological impairments [12].

\section{Concluding remarks}

aSyn and Tau proteins interact, and accumulating evidence suggests that both proteins can feed-forward misfolding and aggregation of each other. In addition, the shared interactome of aSyn and Tau may serve as a pathological point of convergence through which network perturbations, initiated by a variety of misfolding/aggregation triggers such as mutations and abnormal post-translational modifications, interfere with the physiological functions of both proteins and could facilitate development of proteotoxic stress and neurodegenerative changes in the aging brain. Similar cross-talk may occur between other disease-associated aggregating proteins, e.g. between the aSyn-TDP-43 and Tau-TDP43. Future studies should consider the network biology perspective when investigating the pathobiology and phenotypic similarities between synucleinopathies, tauopathies and other neurodegenerative diseases.

\section{Acknowledgements}

This work was supported by the Academy of Finland (grant number 296409) and Finnish Cultural Foundation.

\section{References}

[1] N. Sahni, S. Yi, M. Taipale, J.I. Fuxman Bass, J. Coulombe-Huntington, F. Yang, et al., Widespread macromolecular interaction perturbations in human genetic disorders, Cell 161 (3) (2015) 647-660.

[2] H.A. Lashuel, C.R. Overk, A. Oueslati, E. Masliah, The many faces of alpha-synuclein: from structure and toxicity to therapeutic target, Nat. Rev. Neurosci. 14 (1) (2013) 38-48.

[3] V. Lee, M. Goedert, J. Trojanowski, Neurodegenerative tauopathies, Annu. Rev. Neurosci. 24 (2001) 1121-1159.

[4] S. Fahn, Description of Parkinson's disease as a clinical syndrome, Ann. N. Y. Acad. Sci. 991 (2003) 1-14.

[5] S. Moussaud, D.R. Jones, E.L. Moussaud-Lamodiere, M. Delenclos, O.A. Ross, P.J. McLean, Alpha-synuclein and tau: teammates in neurodegeneration? Mol. Neurodegener. 9 (2014) 43.

[6] Y. Wang, E. Mandelkow, Tau in physiology and pathology, Nat. Rev. Neurosci. 17 (1) (2016) 5-21.

[7] J.L. Guo, V.M. Lee, Cell-to-cell transmission of pathogenic proteins in neurodegenerative diseases, Nat. Med. 20 (2) (2014) 130-138.

[8] W.R. Galpern, A.E. Lang, Interface between tauopathies and synucleinopathies: a tale of two proteins, Ann. Neurol. 59 (3) (2006) 449-458.

[9] A.I. Soto-Ortolaza, O.A. Ross, Genetic susceptibility variants in parkinsonism, Parkinson. Relat. Disord. 22 (Suppl. 1) (2016) S7-S11.

[10] B.I. Giasson, M.S. Forman, M. Higuchi, L.I. Golbe, C.L. Graves, P.T. Kotzbauer, et al., Initiation and synergistic fibrillization of tau and alpha-synuclein, Science 300 (5619) (2003) 636-640.

[11] M. Weingarten, A. Lockwood, S. Hwo, M. Kirschner, A protein factor essential for microtubule assembly, Proc. Natl. Acad. Sci. U. S. A. 72 (5) (1975) 1858-1862

[12] J. Burre, M. Sharma, T. Tsetsenis, V. Buchman, M.R. Etherton, T.C. Sudhof, Alpha-synuclein promotes SNARE-complex assembly in vivo and in vitro, Science 329 (5999) (2010) 1663-1667.

[13] M. Vilar, H.T. Chou, T. Luhrs, S.K. Maji, D. Riek-Loher, R. Verel, et al, The fold of alpha-synuclein fibrils, Proc. Natl. Acad. Sci. U. S. A. 105 (25) (2008) 8637-8642

[14] D. Eisenberg, M. Jucker, The amyloid state of proteins in human diseases, Cell 148 (6) (2012) 1188-1203.

[15] A. Aguzzi, Cell biology: beyond the prion principle, Nature 459 (7249) (2009) 924-925.

[16] J. Guo, V. Lee, Cell-to-cell transmission of pathogenic proteins in neurodegenerative diseases, Nat. Med. 20 (2) (2014) 130-138.

[17] M.G. Spillantini, M.L. Schmidt, V.M. Lee, J.Q. Trojanowski, R. Jakes, M. Goedert, Alpha-synuclein in Lewy bodies, Nature 388 (6645) (1997) 839-840

[18] T.R. Alderson, J.L. Markley, Biophysical characterization of alpha-synuclein and its controversial structure, Intrinsically Disord. Proteins 1 (1) (2013) 18-39.

[19] T. Bartels, J.G. Choi, D.J. Selkoe, Alpha-synuclein occurs physiologically as a helically folded tetramer that resists aggregation, Nature 477 (7362) (2011) 107-110.

[20] U. Dettmer, A.J. Newman, F. Soldner, E.S. Luth, N.C. Kim, V.E. von Saucken, et al., Parkinson-causing alpha-synuclein missense mutations shift native tetramers to monomers as a mechanism for disease initiation, Nat Commun. 6 (2015) 7314.

[21] A.L. Fink, The aggregation and fibrillation of alpha-synuclein, Acc. Chem. Res. 39 (9) (2006) 628-634.

[22] W.S. Davidson, A. Jonas, D.F. Clayton, J.M. George, Stabilization of alpha-synuclein secondary structure upon binding to synthetic membranes, J. Biol. Chem. 273 (16) (1998) 9443-9449.

[23] C. Aisenbrey, T. Borowik, R. Bystrom, M. Bokvist, F. Lindstrom, H. Misiak, et al., How is protein aggregation in amyloidogenic diseases modulated by biological membranes? Eur. Biophys. J. 37 (3) (2008) 247-255.

[24] Y.J. Chai, E. Sierecki, V.M. Tomatis, R.S. Gormal, N. Giles, I.C. Morrow, et al., Munc18-1 is a molecular chaperone for alpha-synuclein, controlling its self-replicating aggregation, J. Cell. Biol. 214 (6) (2016) 705-718.

[25] P.K. Auluck, H.Y. Chan, J.Q. Trojanowski, V.M. Lee, N.M. Bonini, Chaperone suppression of alpha-synuclein toxicity in a Drosophila model for Parkinson's disease, Science 295 (5556) (2002) 865-868.

[26] M. Gerard, A. Deleersnijder, V. Daniels, S. Schreurs, S. Munck, V. Reumers, et al., Inhibition of FK506 binding proteins reduces alpha-synuclein aggregation and Parkinson's disease-like pathology, J. Neurosci. 30 (7) (2010) 2454-2463.

[27] M.H. Savolainen, X. Yan, T.T. Myohanen, H.J. Huttunen, Prolyl oligopeptidase enhances alpha-synuclein dimerization via direct protein-protein interaction, J. Biol. Chem. 290 (8) (2015) 5117-5126.

[28] R. Svarcbahs, U.H. Julku, T.T. Myohanen, Inhibition of prolyl oligopeptidase restores spontaneous motor behavior in the alpha-Synuclein virus vector-based Parkinson's disease mouse model by decreasing 
alpha-Synuclein oligomeric species in mouse brain, J. Neurosci. 36 (49) (2016) 12485-12497

[29] M. Hashimoto, T. Takenouchi, M. Mallory, E. Masliah, A. Takeda, The role of NAC in amyloidogenesis in Alzheimer's disease, Am. J. Pathol. 156 (2) (2000) 734-736.

[30] B.I. Giasson, I.V. Murray, J.Q. Trojanowski, V.M. Lee, A hydrophobic stretch of 12 amino acid residues in the middle of alpha-synuclein is essential for filament assembly, J. Biol. Chem. 276 (4) (2001) 2380-2386.

[31] L. Xu, J. Pu, Alpha-synuclein in Parkinson's disease: from pathogenetic dysfunction to potential clinical application, Parkinson's Dis. 2016 (2016) 1720621.

[32] M.H. Polymeropoulos, C. Lavedan, E. Leroy, S.E. Ide, A. Dehejia, A. Dutra, et al., Mutation in the alpha-synuclein gene identified in families with Parkinson's disease, Science 276 (5321) (1997) 2045-2047.

[33] W. Choi, S. Zibaee, R. Jakes, L.C. Serpell, B. Davletov, R.A. Crowther, et al., Mutation E46K increases phospholipid binding and assembly into filaments of human alpha-synuclein, FEBS Lett. 576 (3) (2004) 363-368.

[34] N.J. Rutherford, B.D. Moore, T.E. Golde, B.I. Giasson, Divergent effects of the H50Q and G51D SNCA mutations on the aggregation of alpha-synuclein, J. Neurochem. 131 (6) (2014) 859-867.

[35] K.A. Conway, J.D. Harper, P.T. Lansbury, Accelerated in vitro fibril formation by a mutant alpha-synuclein linked to early-onset Parkinson disease, Nat. Med. 4 (11) (1998) 1318-1320.

[36] R. Kruger, W. Kuhn, T. Muller, D. Woitalla, M. Graeber, S. Kosel, et al., Ala30Pro mutation in the gene encoding alpha-synuclein in Parkinson's disease, Nat. Genet. 18 (2) (1998) 106-108

[37] W. Li, N. West, E. Colla, O. Pletnikova, J.C. Troncoso, L. Marsh, et al., Aggregation promoting C-terminal truncation of alpha-synuclein is a normal cellular process and is enhanced by the familial Parkinson's disease-linked mutations, Proc. Natl. Acad. Sci. U. S. A. 102 (6) (2005) 2162-2167.

[38] J.P. Daher, M. Ying, R. Banerjee, R.S. McDonald, M.D. Hahn, L. Yang, et al., Conditional transgenic mice expressing C-terminally truncated human alpha-synuclein (alphaSyn119) exhibit reduced striatal dopamine without loss of nigrostriatal pathway dopaminergic neurons, Mol. Neurodegener. 4 (2009) 34.

[39] M. Okochi, J. Walter, A. Koyama, S. Nakajo, M. Baba, T. Iwatsubo, et al., Constitutive phosphorylation of the Parkinson's disease associated alpha-synuclein, J. Biol. Chem. 275 (1) (2000) 390-397.

[40] K.E. Paleologou, A. Oueslati, G. Shakked, C.C. Rospigliosi, H.Y. Kim, G.R. Lamberto, et al., Phosphorylation at S87 is enhanced in synucleinopathies, inhibits alpha-synuclein oligomerization, and influences synuclein-membrane interactions, J. Neurosci. 30 (9) (2010) 3184-3198.

[41] H. Fujiwara, M. Hasegawa, N. Dohmae, A. Kawashima, E. Masliah, M.S. Goldberg, et al., Alpha-synuclein is phosphorylated in synucleinopathy lesions, Nat. Cell. Biol. 4 (2) (2002) 160-164.

[42] A. Oueslati, K.E. Paleologou, B.L. Schneider, P. Aebischer, H.A. Lashuel, Mimicking phosphorylation at serine 87 inhibits the aggregation of human alpha-synuclein and protects against its toxicity in a rat model of Parkinson's disease, J. Neurosci. 32 (5) (2012) 1536-1544.

[43] S. Tenreiro, M.M. Reimao-Pinto, P. Antas, J. Rino, D. Wawrzycka, D. Macedo et al., Phosphorylation modulates clearance of alpha-synuclein inclusions in a yeast model of Parkinson's disease, PLoS Genet. 10 (5) (2014) e1004302.

[44] H.L. Smith, W. Li, M.E. Cheetham, Molecular chaperones and neuronal proteostasis, Semin. Cell. Dev. Biol. 40 (2015) 142-152.

[45] M. Lundblad, M. Decressac, B. Mattsson, A. Bjorklund, Impaired neurotransmission caused by overexpression of alpha-synuclein in nigral dopamine neurons, Proc. Natl. Acad. Sci. U. S. A. 109 (9) (2012) 3213-3219

[46] R.G. Perez, J.C. Waymire, E. Lin, J.J. Liu, F. Guo, M.J. Zigmond, A role for alpha-synuclein in the regulation of dopamine biosynthesis, J. Neurosci. 22 (8) (2002) 3090-3099.

[47] X. Peng, R. Tehranian, P. Dietrich, L. Stefanis, R.G. Perez, Alpha-synuclein activation of protein phosphatase 2 A reduces tyrosine hydroxylase phosphorylation in dopaminergic cells, J. Cell. Sci. 118 (Pt 15)(2005) 3523-3530

[48] V.M. Nemani, W. Lu, V. Berge, K. Nakamura, B. Onoa, M.K. Lee, et al., Increased expression of alpha-synuclein reduces neurotransmitter release by inhibiting synaptic vesicle reclustering after endocytosis, Neuron 65 (1) (2010) 66-79

49] K.E. Larsen, Y. Schmitz, M.D. Troyer, E. Mosharov, P. Dietrich, A.Z. Quazi, et al., Alpha-synuclein overexpression in PC12 and chromaffin cells impairs catecholamine release by interfering with a late step in exocytosis, J. Neurosci. 26 (46) (2006) 11915-11922.

[50] K. Beyer, Alpha-synuclein structure, posttranslational modification and alternative splicing as aggregation enhancers, Acta Neuropathol. 112 (3) (2006) 237-251.

[51] M. Kriebel, J. Wuchter, S. Trinks, H. Volkmer, Neurofascin: a switch between neuronal plasticity and stability, Int. J. Biochem. Cell. Biol. 44 (5) (2012) 694-697.

[52] W. Yang, G. Wang, C.E. Wang, X. Guo, P. Yin, J. Gao, et al., Mutant alpha-synuclein causes age-dependent neuropathology in monkey brain, J. Neurosci. 35 (21) (2015) 8345-8358.

[53] M. Stockl, P. Fischer, E. Wanker, A. Herrmann, Alpha-synuclein selectively binds to anionic phospholipids embedded in liquid-disordered domains, J. Mol. Biol. 375 (5) (2008) 1394-1404.
[54] D. Ysselstein, M. Joshi, V. Mishra, A.M. Griggs, J.M. Asiago, G.P. McCabe, et al., Effects of impaired membrane interactions on alpha-synuclein aggregation and neurotoxicity, Neurobiol. Dis. 79 (2015) 150-163.

[55] E. Kontopoulos, J.D. Parvin, M.B. Feany, Alpha-synuclein acts in the nucleus to inhibit histone acetylation and promote neurotoxicity, Hum. Mol. Genet. 15 (20) (2006) 3012-3023.

[56] J.P. Anderson, D.E. Walker, J.M. Goldstein, R. de Laat, K. Banducci, R.J. Caccavello, et al., Phosphorylation of Ser-129 is the dominant pathological modification of alpha-synuclein in familial and sporadic Lewy body disease, J. Biol. Chem. 281 (40) (2006) 29739-29752.

[57] M.A. McFarland, C.E. Ellis, S.P. Markey, R.L. Nussbaum, Proteomics analysis identifies phosphorylation-dependent alpha-synuclein protein interactions, Mol. Cell. Proteom. 7 (11) (2008) 2123-2137.

[58] M.S. Parihar, A. Parihar, M. Fujita, M. Hashimoto, P. Ghafourifar, Mitochondrial association of alpha-synuclein causes oxidative stress, Cell. Mol. Life Sci. 65 (7-8) (2008) 1272-1284.

[59] C. Betzer, A.J. Movius, M. Shi, W.P. Gai, J. Zhang, P.H. Jensen, Identification of synaptosomal proteins binding to monomeric and oligomeric alpha-synuclein, PLoS One 10 (2) (2015) e0116473.

[60] K.J. Kinghorn, A.M. Asghari, J.I. Castillo-Quan, The emerging role of autophagic-lysosomal dysfunction in Gaucher disease and Parkinson's disease, Neural Regen. Res. 12 (3) (2017) 380-384.

[61] A.H. Schapira, Glucocerebrosidase and Parkinson disease: recent advances, Mol. Cell. Neurosci. 66 (Pt A) (2015) 37-42.

[62] T.L. Yap, J.M. Gruschus, A. Velayati, W. Westbroek, E. Goldin, N. Moaven, et al., Alpha-synuclein interacts with Glucocerebrosidase providing a molecular link between Parkinson and Gaucher diseases, J. Biol. Chem. 286 32) (2011) 28080-28088.

[63] E.J. Bae, N.Y. Yang, C. Lee, H.J. Lee, S. Kim, S.P. Sardi, et al., Loss of glucocerebrosidase 1 activity causes lysosomal dysfunction and alpha-synuclein aggregation, Exp. Mol. Med. 47 (2015) e188.

[64] S.P. Sardi, S.H. Cheng, L.S. Shihabuddin, Gaucher-related synucleinopathies: the examination of sporadic neurodegeneration from a rare (disease) angle, Prog. Neurobiol. 125 (2015) 47-62.

[65] T. Lopes da Fonseca, R. Pinho, T.F. Outeiro, A familial ATP13A2 mutation enhances alpha-synuclein aggregation and promotes cell death, Hum. Mol. Genet. 25 (14) (2016) 2959-2971

[66] T. Tsunemi, K. Hamada, D. Krainc, ATP13A2/PARK9 regulates secretion of exosomes and alpha-synuclein, J. Neurosci. 34 (46)(2014) 15281-15287.

[67] R. Neve, P. Harris, K. Kosik, D. Kurnit, T. Donlon, Identification of cDNA clones for the human microtubule-associated protein tau and chromosomal localization of the genes for tau and microtubule-associated protein 2, Brain Res. 387 (3) (1986) 271-280.

[68] E.M. Mandelkow, O. Schweers, G. Drewes, J. Biernat, N. Gustke, B. Trinczek, et al., Structure, microtubule interactions, and phosphorylation of tau protein, Ann. N. Y. Acad. Sci. 777 (1996) 96-106.

[69] M. Goedert, R. Jakes, M.G. Spillantini, M. Hasegawa, M.J. Smith, R.A. Crowther, Assembly of microtubule-associated protein tau into Alzheimer-like filaments induced by sulphated glycosaminoglycans, Nature 383 (6600) (1996) 550-553.

[70] D.M. Wilson, L.I. Binder, Free fatty acids stimulate the polymerization of tau and amyloid beta peptides. In vitro evidence for a common effector of pathogenesis in Alzheimer's disease, Am. J. Pathol. 150 (6) (1997) 2181-2195.

[71] C. Bancher, C. Brunner, H. Lassmann, H. Budka, K. Jellinger, G. Wiche, et al., Accumulation of abnormally phosphorylated tau precedes the formation of neurofibrillary tangles in Alzheimer's disease, Brain Res. 477 (1-2) (1989) 90-99.

[72] T. Arendt, J. Stieler, A.M. Strijkstra, R.A. Hut, J. Rudiger, E.A. Van der Zee, et al., Reversible paired helical filament-like phosphorylation of tau is an adaptive process associated with neuronal plasticity in hibernating animals, J. Neurosci. 23 (18) (2003) 6972-6981.

[73] G. Simic, M. Babic Leko, S. Wray, C. Harrington, I. Delalle, N. Jovanov-Milosevic, et al., Tau protein hyperphosphorylation and aggregation in Alzheimer's disease and other tauopathies, and possible neuroprotective strategies, Biomolecules 6 (1) (2016) 6 .

[74] A.W.P. Fitzpatrick, B. Falcon, S. He, A.G. Murzin, G. Murshudov, H.] Garringer, et al., Cryo-EM structures of tau filaments from Alzheimer's disease, Nature 547 (7662) (2017) 185-190.

[75] M. von Bergen, P. Friedhoff, J. Biernat, J. Heberle, E.M. Mandelkow, E. Mandelkow, Assembly of tau protein into Alzheimer paired helical filaments depends on a local sequence motif ((306)VQIVYK(311)) forming beta structure, Proc. Natl. Acad. Sci. U. S. A. 97 (10) (2000) 5129-5134.

[76] D. Fischer, M.D. Mukrasch, M. von Bergen, A. Klos-Witkowska, J. Biernat, C. Griesinger, et al., Structural and microtubule binding properties of tau mutants of frontotemporal dementias, Biochemistry 46 (10) (2007) 2574-2582.

[77] M.S. Wolfe, Tau mutations in neurodegenerative diseases, J. Biol. Chem. 284 (10) (2009) 6021-6025

[78] N. Zilka, P. Filipcik, P. Koson, L. Fialova, R. Skrabana, M. Zilkova, et al. Truncated tau from sporadic Alzheimer's disease suffices to drive neurofibrillary degeneration in vivo, FEBS Lett. 580 (15) (2006) 3582-3588.

[79] A. de Calignon, L.M. Fox, R. Pitstick, G.A. Carlson, B.J. Bacskai, T.L. Spires-Jones, et al., Caspase activation precedes and leads to tangles, Nature 464 (7292) (2010) 1201-1204. 
[80] L. Bakota, R. Brandt, Tau biology and tau-directed therapies for Alzheimer's disease, Drugs 76 (3) (2016) 301-313.

[81] T. Ahmed, A. Van der Jeugd, D. Blum, M.C. Galas, R. D'Hooge, L. Buee, et al., Cognition and hippocampal synaptic plasticity in mice with a homozygous tau deletion, Neurobiol. Aging 35 (11) (2014) 2474-2478.

[82] S. Mondragon-Rodriguez, E. Trillaud-Doppia, A. Dudilot, C. Bourgeois, M. Lauzon, N. Leclerc, et al., Interaction of endogenous tau protein with synaptic proteins is regulated by $\mathrm{N}$-methyl-D-aspartate receptor-dependent tau phosphorylation, J. Biol. Chem. 287 (38) (2012) 32040-32053.

[83] Y. Takei, J. Teng, A. Harada, N. Hirokawa, Defects in axonal elongation and neuronal migration in mice with disrupted tau and map1b genes, J. Cell. Biol. 150 (5) (2000) 989-1000.

[84] S. Meier, M. Bell, D.N. Lyons, J. Rodriguez-Rivera, A. Ingram, S.N. Fontaine, et al., Pathological tau promotes neuronal damage by impairing ribosomal function and decreasing protein synthesis, J. Neurosci. 36 (3) (2016) 1001-1007.

[85] D.P. Hanger, B.H. Anderton, W. Noble, Tau phosphorylation: the therapeutic challenge for neurodegenerative disease, Trends Mol. Med. 15 (3) (2009) 112-119.

[86] C.A. Dickey, A. Kamal, K. Lundgren, N. Klosak, R.M. Bailey, J. Dunmore, et al., The high-affinity HSP90-CHIP complex recognizes and selectively degrades phosphorylated tau client proteins, J. Clin. Invest. 117 (3) (2007) 648-658.

[87] P.J. Lu, G. Wulf, X.Z. Zhou, P. Davies, K.P. Lu, The prolyl isomerase Pin1 restores the function of Alzheimer-associated phosphorylated tau protein, Nature 399 (6738) (1999) 784-788.

[88] Y.C. Liou, A. Sun, A. Ryo, X.Z. Zhou, Z.X. Yu, H.K. Huang, et al., Role of the prolyl isomerase Pin1 in protecting against age-dependent neurodegeneration, Nature 424 (6948) (2003) 556-561.

[89] L.M. Ittner, Y.D. Ke, J. Gotz, Phosphorylated tau interacts with c-Jun N-terminal kinase-interacting protein 1 (JIP1) in Alzheimer disease, J. Biol. Chem. 284 (31) (2009) 20909-20916.

[90] A. Sultan, F. Nesslany, M. Violet, S. Begard, A. Loyens, S. Talahari, et al., Nuclear tau, a key player in neuronal DNA protection, J. Biol. Chem. 286 (6) (2011) 4566-4575

[91] M. Perez, I. Santa-Maria, E. Gomez de Barreda, X. Zhu, R. Cuadros, J.R. Cabrero, et al., Tau-an inhibitor of deacetylase HDAC6 function, J. Neurochem. 109 (6) (2009) 1756-1766.

[92] J. Leyk, O. Goldbaum, M. Noack, C. Richter-Landsberg, Inhibition of HDAC6 modifies tau inclusion body formation and impairs autophagic clearance, J. Mol. Neurosci. 55 (4) (2015) 1031-1046.

[93] P. Wang, G. Joberty, A. Buist, A. Vanoosthuyse, I.C. Stancu, B. Vasconcelos, et al., Tau interactome mapping based identification of Otub1 as tau deubiquitinase involved in accumulation of pathological tau forms in vitro and in vivo, Acta Neuropathol. 133 (5) (2017) 731-749.

[94] L.M. Ittner, Y.D. Ke, F. Delerue, M. Bi, A. Gladbach, J. van Eersel, et al., Dendritic function of tau mediates amyloid-beta toxicity in Alzheimer's disease mouse models, Cell 142 (3) (2010) 387-397.

[95] R. Williamson, T. Scales, B. Clark, G. Gibb, C. Reynolds, S. Kellie, et al., Rapid tyrosine phosphorylation of neuronal proteins including tau and focal adhesion kinase in response to amyloid-beta peptide exposure: involvement of Src family protein kinases, J. Neurosci. 22 (1) (2002) $10-20$.

[96] H. Zempel, J. Luedtke, Y. Kumar, J. Biernat, H. Dawson, E. Mandelkow, et al., Amyloid-beta oligomers induce synaptic damage via tau-dependent microtubule severing by TTLL6 and spastin, EMBO J. 32 (22) (2013) 2920-2937

[97] M. Goedert, S. Satumtira, R. Jakes, M.J. Smith, C. Kamibayashi, C.L. White 3rd, et al., Reduced binding of protein phosphatase $2 \mathrm{~A}$ to tau protein with frontotemporal dementia and parkinsonism linked to chromosome 17 mutations, J. Neurochem. 75 (5) (2000) 2155-2162.

[98] A. Salminen, J. Ojala, K. Kaarniranta, M. Hiltunen, H. Soininen, Hsp90 regulates tau pathology through co-chaperone complexes in Alzheimer's disease, Prog. Neurobiol. 93 (1) (2011) 99-110.

[99] A.S. Chesser, S.M. Pritchard, G.V. Johnson, Tau clearance mechanisms and their possible role in the pathogenesis of Alzheimer disease, Front. Neurol. 4 (2013) 122.

[100] C.G. Gunawardana, M. Mehrabian, X. Wang, I. Mueller, I.B. Lubambo, J.E Jonkman, et al., The human tau interactome: binding to the ribonucleoproteome, and impaired binding of the proline-to-leucine mutant at position $301(\mathrm{P} 301 \mathrm{~L})$ to chaperones and the proteasome, Mol. Cell. Proteom. 14 (11) (2015) 3000-3014.

[101] J. Lim, M. Balastik, T.H. Lee, K. Nakamura, Y.C. Liou, A. Sun, et al., Pin1 has opposite effects on wild-type and P301L tau stability and tauopathy, J. Clin. Invest. 118 (5) (2008) 1877-1889.

[102] A. Gauthier-Kemper, C. Weissmann, N. Golovyashkina, Z. Sebo-Lemke, G. Drewes, V. Gerke, et al., The frontotemporal dementia mutation R406W blocks tau's interaction with the membrane in an annexin A2-dependent manner, J. Cell. Biol. 192 (4) (2011) 647-661.

[103] C.A. Brunello, X. Yan, H.J. Huttunen, Internalized tau sensitizes cells to stress by promoting formation and stability of stress granules, Sci. Rep. 6 (2016) 30498

[104] T. Vanderweyde, D.J. Apicco, K. Youmans-Kidder, P.E. Ash, C. Cook, E. Lummertz da Rocha, et al., Interaction of tau with the RNA-Binding protein TIA1 regulates tau pathophysiology and toxicity, Cell. Rep. 15 (7) (2016) 1455-1466.
[105] E.A. Kikis, T. Gidalevitz, R.I. Morimoto, Protein homeostasis in models of aging and age-related conformational disease, Adv. Exp. Med. Biol. 694 (2010) 138-159.

[106] C.F. Lippa, H. Fujiwara, D.M. Mann, B. Giasson, M. Baba, M.L. Schmidt, et al., Lewy bodies contain altered alpha-synuclein in brains of many familial Alzheimer's disease patients with mutations in presenilin and amyloid precursor protein genes, Am. J. Pathol. 153 (5) (1998) 1365-1370.

[107] C.F. Lippa, M.L. Schmidt, V.M. Lee, J.Q. Trojanowski, Antibodies to alpha-synuclein detect Lewy bodies in many Down's syndrome brains with Alzheimer's disease, Ann. Neurol. 45 (3) (1999) 353-357.

[108] M.S. Forman, M.L. Schmidt, S. Kasturi, D.P. Perl, V.M. Lee, J.Q. Trojanowski, Tau and alpha-synuclein pathology in amygdala of Parkinsonism-dementia complex patients of Guam, Am. J. Pathol. 160 (5) (2002) 1725-1731.

[109] T. Ishizawa, P. Mattila, P. Davies, D. Wang, D.W. Dickson, Colocalization of tau and alpha-synuclein epitopes in Lewy bodies, J. Neuropathol. Exp. Neurol. 62 (4) (2003) 389-397.

[110] D. Aarsland, J. Zaccai, C. Brayne, A systematic review of prevalence studies of dementia in Parkinson's disease, Mov. Disord. 20 (10) (2005) 1255-1263.

[111] J.B. Leverenz, J.F. Quinn, C. Zabetian, J. Zhang, K.S. Montine, T.J. Montine, Cognitive impairment and dementia in patients with Parkinson disease, Curr. Top. Med. Chem. 9 (10) (2009) 903-912.

[112] J.B. Leverenz, R. Hamilton, D.W. Tsuang, A. Schantz, D. Vavrek, E.B. Larson, et al., Empiric refinement of the pathologic assessment of Lewy-related pathology in the dementia patient, Brain Pathol. 18 (2) (2008) 220-224.

[113] R.L. Hamilton, Lewy bodies in Alzheimer's disease: a neuropathological review of 145 cases using alpha-synuclein immunohistochemistry, Brain Pathol. 10 (3) (2000) 378-384.

[114] C. Bancher, H. Braak, P. Fischer, K.A. Jellinger, Neuropathological staging of Alzheimer lesions and intellectual status in Alzheimer's and Parkinson's disease patients, Neurosci. Lett. 162 (1-2) (1993) 179-182.

[115] J.J. Zarranz, J. Alegre, J.C. Gomez-Esteban, E. Lezcano, R. Ros, I. Ampuero, et al., The new mutation, E46K, of alpha-synuclein causes Parkinson and Lewy body dementia, Ann. Neurol. 55 (2) (2004) 164-173.

[116] S. Fujioka, K. Ogaki, P.M. Tacik, R.J. Uitti, O.A. Ross, Z.K. Wszolek, Update on novel familial forms of Parkinson's disease and multiple system atrophy, Parkinson. Relat. Disord. 20 (Suppl. 1) (2014) S29-S34.

[117] M.G. Spillantini, J.R. Murrell, M. Goedert, M.R. Farlow, A. Klug, B. Ghetti, Mutation in the tau gene in familial multiple system tauopathy with presenile dementia, Proc. Natl. Acad. Sci. U. S. A. 95 (13) (1998) 7737-7741.

[118] C. Dumanchin, A. Camuzat, D. Campion, P. Verpillat, D. Hannequin, B. Dubois, et al., Segregation of a missense mutation in the microtubule-associated protein tau gene with familial frontotemporal dementia and parkinsonism, Hum. Mol. Genet. 7 (11) (1998) 1825-1829.

[119] P.H. Jensen, H. Hager, M.S. Nielsen, P. Hojrup, J. Gliemann, R. Jakes, Alpha-synuclein binds to tau and stimulates the protein kinase A-catalyzed tau phosphorylation of serine residues 262 and 356, J. Biol. Chem. 274 (36) (1999) 25481-25489.

[120] P.T. Kotzbauer, B.I. Giasson, A.V. Kravitz, L.I. Golbe, M.H. Mark, J.Q. Trojanowski, et al., Fibrillization of alpha-synuclein and tau in familial Parkinson's disease caused by the A53T alpha-synuclein mutation, Exp. Neurol. 187 (2) (2004) 279-288.

[121] N. Badiola, R.M. de Oliveira, F. Herrera, C. Guardia-Laguarta, S.A. Goncalves M. Pera, et al., Tau enhances alpha-synuclein aggregation and toxicity in cellular models of synucleinopathy, PLoS One 6 (10) (2011) e26609.

[122] H.Y. Qureshi, H.K. Paudel, Parkinsonian neurotoxin 1-methyl-4-phenyl-1,2,3,6-tetrahydropyridine (MPTP) and alpha-synuclein mutations promote tau protein phosphorylation at Ser262 and destabilize microtubule cytoskeleton in vitro, J. Biol. Chem. 286 (7) (2011) 5055-5068.

[123] T. Duka, M. Rusnak, R.E. Drolet, V. Duka, C. Wersinger, J.L. Goudreau, et al., Alpha-synuclein induces hyperphosphorylation of tau in the MPTP model of parkinsonism, FASEB J. 20 (13) (2006) 2302-2312.

[124] T. Duka, V. Duka, J.N. Joyce, A. Sidhu, Alpha-synuclein contributes to GSK-3beta-catalyzed tau phosphorylation in Parkinson's disease models, FASEB J. 23 (9) (2009) 2820-2830.

[125] E.A. Waxman, B.I. Giasson, Induction of intracellular tau aggregation is promoted by alpha-synuclein seeds and provides novel insights into the hyperphosphorylation of tau, J. Neurosci. 31 (21) (2011) 7604-7618.

[126] S.N. Fontaine, D. Zheng, J.J. Sabbagh, M.D. Martin, D. Chaput, A. Darling, et al., DnaJ/Hsc70 chaperone complexes control the extracellular release of neurodegenerative-associated proteins, EMBO J. 35 (14) (2016) 1537-1549.

[127] M.G. Spillantini, R.A. Crowther, R. Jakes, M. Hasegawa, M. Goedert, Alpha-synuclein in filamentous inclusions of Lewy bodies from Parkinson's disease and dementia with Lewy bodies, Proc. Natl. Acad. Sci. U. S. A. 95 (11) (1998) 6469-6473.

[128] M. Gearing, M. Lynn, S.S. Mirra, Neurofibrillary pathology in Alzheimer disease with Lewy bodies: two subgroups, Arch Neurol. 56 (2) (1999) 203-208.

[129] J.L. Guo, D.J. Covell, J.P. Daniels, M. Iba, A. Stieber, B. Zhang, et al., Distinct alpha-synuclein strains differentially promote tau inclusions in neurons, Cell 154 (1) (2013) 103-117.

[130] X. Zhou, J. Menche, A.L. Barabasi, A. Sharma, Human symptoms-disease network, Nat. Commun. 5 (2014) 4212.

[131] S. Kuzuhara, H. Mori, N. Izumiyama, M. Yoshimura, Y. Ihara, Lewy bodies are ubiquitinated. A light and electron microscopic immunocytochemical study, Acta Neuropathol. 75 (4) (1988) 345-353. 
[132] H. Mori, J. Kondo, Y. Ihara, Ubiquitin is a component of paired helical filaments in Alzheimer's disease, Science 235 (4796) (1987) 1641-1644.

[133] S. Bukhatwa, B.Y. Zeng, S. Rose, P. Jenner, A comparison of changes in proteasomal subunit expression in the substantia nigra in Parkinson's disease, multiple system atrophy and progressive supranuclear palsy, Brain Res. 1326 (2010) 174-183.

[134] S. Oddo, The ubiquitin-proteasome system in Alzheimer's disease, J. Cell. Mol. Med. 12 (2) (2008) 363-373.

[135] M.A. Alim, M.S. Hossain, K. Arima, K. Takeda, Y. Izumiyama, M. Nakamura, et al., Tubulin seeds alpha-synuclein fibril formation, J. Biol. Chem. 277 (3) (2002) 2112-2117.

[136] Y. Zhou, G. Gu, D.R. Goodlett, T. Zhang, C. Pan, T.J. Montine, et al., Analysis of alpha-synuclein-associated proteins by quantitative proteomics, J. Biol. Chem. 279 (37) (2004) 39155-39164.

[137] M.A. Alim, Q.L. Ma, K. Takeda, T. Aizawa, M. Matsubara, M. Nakamura, et al., Demonstration of a role for alpha-synuclein as a functional microtubule-associated protein, J. Alzheimers Dis. 6 (4) (2004) 435-442, discussion 443-9.

[138] J. Gotz, A. Probst, M.G. Spillantini, T. Schafer, R. Jakes, K. Burki, et al., Somatodendritic localization and hyperphosphorylation of tau protein in transgenic mice expressing the longest human brain tau isoform, EMBO J. 14 (7) (1995) 1304-1313.

[139] G. Andringa, F. Du, T.N. Chase, M.C. Bennett, Mapping of rat brain using the Synuclein-1 monoclonal antibody reveals somatodendritic expression of alpha-synuclein in populations of neurons homologous to those vulnerable to Lewy body formation in human synucleopathies, J. Neuropathol. Exp. Neurol. 62 (10) (2003) 1060-1075.

[140] R. Sharon, I. Bar-Joseph, G.E. Mirick, C.N. Serhan, D.J. Selkoe, Altered fatty acid composition of dopaminergic neurons expressing alpha-synuclein and human brains with alpha-synucleinopathies, J. Biol. Chem. 278 (50) (2003) 49874-49881.

[141] J. Poirier, Apolipoprotein E and cholesterol metabolism in the pathogenesis and treatment of Alzheimer's disease, Trends Mol. Med. 9 (3) (2003) 94-101.

[142] K. Kamino, T. Tanaka, T. Kida, M. Ohkochi, H. Tanii, T. Kudo, et al., The role of lipid metabolism in Alzheimer's disease, Nihon shinkei seishin yakurigaku zasshi $=$ Jpn. J. Psychopharmacol. 22 (4) (2002) 103-110.

[143] W.P. Gai, H.X. Yuan, X.Q. Li, J.T. Power, P.C. Blumbergs, P.H. Jensen, In situ and in vitro study of colocalization and segregation of alpha-synuclein, ubiquitin, and lipids in Lewy bodies, Exp. Neurol. 166 (2) (2000) 324-333.

[144] P. Foley, Lipids in Alzheimer's disease: a century-old story, Biochim. Biophys. Acta 1801 (8) (2010) 750-753.

[145] G. Kunze, P. Barre, H.A. Scheidt, L. Thomas, D. Eliezer, D. Huster, Binding of the three-repeat domain of tau to phospholipid membranes induces an aggregated-like state of the protein, Biochim. Biophys. Acta 1818 (9) (2012) 2302-2313.

[146] C.N. Chirita, M. Necula, J. Kuret, Anionic micelles and vesicles induce tau fibrillization in vitro, J. Biol. Chem. 278 (28) (2003) 25644-25650.

[147] N.B. Cole, D.D. Murphy, T. Grider, S. Rueter, D. Brasaemle, R.L. Nussbaum, Lipid droplet binding and oligomerization properties of the Parkinson's disease protein alpha-synuclein, J. Biol. Chem. 277 (8) (2002) 6344-6352.

[148] H.J. Lee, C. Choi, S.J. Lee, Membrane-bound alpha-synuclein has a high aggregation propensity and the ability to seed the aggregation of the cytosolic form, J. Biol. Chem. 277 (1) (2002) 671-678.

[149] T.T. Ding, S.J. Lee, J.C. Rochet, P.T. Lansbury Jr., Annular alpha-synuclein protofibrils are produced when spherical protofibrils are incubated in solution or bound to brain-derived membranes, Biochemistry 41 (32) (2002) 10209-10217.

[150] I.F. Tsigelny, Y. Sharikov, W. Wrasidlo, T. Gonzalez, P.A. Desplats, L. Crews, et al., Role of alpha-synuclein penetration into the membrane in the mechanisms of oligomer pore formation, FEBS J. 279 (6) (2012) 1000-1013.

[151] H.Y. Kim, M.K. Cho, A. Kumar, E. Maier, C. Siebenhaar, S. Becker, et al., Structural properties of pore-forming oligomers of alpha-synuclein, J. Am. Chem. Soc. 131 (47) (2009) 17482-17489.

[152] K. Flach, I. Hilbrich, A. Schiffmann, U. Gartner, M. Kruger, M. Leonhardt, et al., Tau oligomers impair artificial membrane integrity and cellular viability, J. Biol. Chem. 287 (52) (2012) 43223-43233.

[153] M. Hashiguchi, K. Sobue, H.K. Paudel, 14-3-3zeta is an effector of tau protein phosphorylation, J. Biol. Chem. 275 (33) (2000) 25247-25254.

[154] Z. Xu, K. Graham, M. Foote, F. Liang, R. Rizkallah, M. Hurt, et al., 14-3-3 protein targets misfolded chaperone-associated proteins to aggresomes, J. Cell. Sci. 126 (Pt 18) (2013) 4173-4186.

[155] N. Ostrerova, L. Petrucelli, M. Farrer, N. Mehta, P. Choi, J. Hardy, et al., Alpha-synuclein shares physical and functional homology with 14-3-3 proteins, J. Neurosci. 19 (14) (1999) 5782-5791.

[156] R.M. Bailey, J.P. Covy, H.L. Melrose, L. Rousseau, R. Watkinson, J. Knight, et al., LRRK2 phosphorylates novel tau epitopes and promotes tauopathy, Acta Neuropathol. 126 (6) (2013) 809-827.

[157] H. Qing, W. Wong, E.G. McGeer, P.L. McGeer, Lrrk2 phosphorylates alpha synuclein at serine 129: Parkinson disease implications, Biochem. Biophys. Res. Commun. 387 (1) (2009) 149-152.

[158] F. Kawakami, T. Yabata, E. Ohta, T. Maekawa, N. Shimada, M. Suzuki, et al., LRRK2 phosphorylates tubulin-associated tau but not the free molecule: LRRK2-mediated regulation of the tau-tubulin association and neurite outgrowth, PLoS One 7 (1) (2012) e30834.

[159] F. Kawakami, N. Shimada, E. Ohta, G. Kagiya, R. Kawashima, T. Maekawa, et al., Leucine-rich repeat kinase 2 regulates tau phosphorylation through direct activation of glycogen synthase kinase-3beta, FEBS J. 281 (1) (2014) 3-13.

[160] F. Kawakami, M. Suzuki, N. Shimada, G. Kagiya, E. Ohta, K. Tamura, et al., Stimulatory effect of alpha-synuclein on the tau-phosphorylation by GSK-3beta, FEBS J. 278 (24) (2011) 4895-4904.

[161] P. Reinhardt, B. Schmid, L.F. Burbulla, D.C. Schondorf, L. Wagner, M. Glatza, et al., Genetic correction of a LRRK2 mutation in human iPSCs links parkinsonian neurodegeneration to ERK-dependent changes in gene expression, Cell Stem Cell 12 (3) (2013) 354-367.

[162] E. Greggio, M. Bisaglia, L. Civiero, L. Bubacco, Leucine-rich repeat kinase 2 and alpha-synuclein: intersecting pathways in the pathogenesis of Parkinson's disease? Mol. Neurodegener. 6 (1) (2011) 6.

[163] L. Qiang, W. Yu, A. Andreadis, M. Luo, P.W. Baas, Tau protects microtubules in the axon from severing by katanin, J. Neurosci. 26 (12) (2006) 3120-3129.

[164] P. Lei, S. Ayton, S. Moon, Q. Zhang, I. Volitakis, D.I. Finkelstein, et al., Motor and cognitive deficits in aged tau knockout mice in two background strains, Mol. Neurodegener. 9 (2014) 29.

[165] D.D. Murphy, S.M. Rueter, J.Q. Trojanowski, V.M. Lee, Synucleins are developmentally expressed, and alpha-synuclein regulates the size of the presynaptic vesicular pool in primary hippocampal neurons, J. Neurosci. 20 (9) (2000) 3214-3220.

[166] A. Abeliovich, Y. Schmitz, I. Farinas, D. Choi-Lundberg, W.H. Ho, P.E. Castillo, et al., Mice lacking alpha-synuclein display functional deficits in the nigrostriatal dopamine system, Neuron 25 (1) (2000) 239-252. 